\title{
Prediction of in vivo developmental toxicity of all-trans-retinoic acid based on in vitro toxicity data and in silico physiologically based kinetic modeling
}

\author{
Jochem Louisse $\cdot$ Sieto Bosgra $\cdot$ Bas J. Blaauboer $\cdot$ \\ Ivonne M. C. M. Rietjens • Miriam Verwei
}

Received: 13 February 2014 / Accepted: 28 May 2014 / Published online: 17 June 2014

(C) Springer-Verlag Berlin Heidelberg 2014

\begin{abstract}
The use of laboratory animals for toxicity testing in chemical safety assessment meets increasing ethical, economic and legislative constraints. The development, validation and application of reliable alternatives for in vivo toxicity testing are therefore urgently needed. In order to use toxicity data obtained from in vitro assays for risk assessment, in vitro concentration-response data need to be translated into in vivo dose-response data that are needed to obtain points of departure for risk assessment, like a benchmark dose (BMD). In the present study, we translated in vitro concentration-response data of the retinoid all-trans-retinoic acid (ATRA), obtained in the differentiation assay of the embryonic stem cell test, into in vivo dose-response data using a physiologically based kinetic model for rat and human that is mainly based on kinetic model parameter values derived using in vitro techniques. The predicted in vivo dose-response data were used for BMD modeling, and the obtained $\mathrm{BMDL}_{10}$
\end{abstract}

Electronic supplementary material The online version of this article (doi:10.1007/s00204-014-1289-4) contains supplementary material, which is available to authorized users.

J. Louisse $(\bowtie) \cdot$ I. M. C. M. Rietjens

Division of Toxicology, Wageningen University, Tuinlaan 5, 6703

HE Wageningen, The Netherlands

e-mail: jochem.louisse@wur.nl

J. Louisse $\cdot$ S. Bosgra $\cdot$ M. Verwei

TNO, PO Box 360, 3700 AJ Zeist, The Netherlands

B. J. Blaauboer

Institute for Risk Assessment Sciences (IRAS), Utrecht

University, PO Box 80176, 3508 TD Utrecht, The Netherlands values [lower limit of the $95 \%$ confidence interval on the BMD at which a benchmark response equivalent to a $10 \%$ effect size $\left(\mathrm{BMR}_{10}\right)$ is reached $\left(\mathrm{BMD}_{10}\right)$ ] for rat were compared with $\mathrm{BMDL}_{10}$ values derived from in vivo developmental toxicity data in rats reported in the literature. The results show that the $\mathrm{BMDL}_{10}$ values from predicted dose-response data differ about sixfold from the $\mathrm{BMDL}_{10}$ values obtained from in vivo data, pointing at the feasibility of using a combined in vitro-in silico approach for defining a point of departure for toxicological risk assessment.

Keywords In vitro-in vivo extrapolation · Developmental toxicity $\cdot$ All-trans-retinoic acid · Physiologically based kinetic modeling $\cdot$ Reverse dosimetry $\cdot$ Solid phase microextraction
Abbreviations
3Rs Replacement, reduction and refinement
ATRA All-trans-retinoic acid
AUC Area under the concentration-time curve
BMD Benchmark dose
$\mathrm{BMDL}_{10}$ Lower limit of the $95 \%$ confidence interval on the BMD at which a benchmark response equivalent to a $10 \%$ effect size $\left(\mathrm{BMR}_{10}\right)$ is reached $\left(\mathrm{BMD}_{10}\right)$
$C_{\max } \quad$ Maximum concentration
CYP Cytochrome P450
MPPGL Microsomal protein per gram of liver
$P_{\text {app }} \quad$ Apparent permeability
PBK Physiologically based kinetic
PDMS Polydimethylsiloxane
POD Point of departure
SPME Solid-phase microextraction
UGT Uridine 5'-diphospho-glucuronosyltransferase 


\section{Introduction}

For the registration of chemicals, such as pharmaceuticals, industrial chemicals, food additives, cosmetic ingredients and pesticides, regulatory agencies require safety studies performed in laboratory animals. The majority of these animals are used for reproductive and developmental toxicity testing (Van der Jagt et al. 2004). The use of laboratory animals for toxicity testing meets increasing ethical, economic and legislative constraints, indicating that the development, validation and application of reliable alternatives for in vivo studies is urgently needed. Currently, in vitro assays are considered to be useful in the development and early safety testing of new chemicals and for setting priorities for toxicity testing of existing industrial chemicals, but in vitro assays are hardly used in toxicological risk assessment. One important reason is that in vitro assays provide concentration-response data, whereas in vivo dose-response data are required for risk assessment. Therefore, in vitro toxic effect concentrations need to be translated into in vivo toxic dose levels, in order to implement in vitro assays in toxicological risk assessment.

The translation of in vitro concentrations into in vivo doses can be achieved using physiologically based kinetic (PBK) modeling with a reverse dosimetry approach (DeJongh et al. 1999; Forsby and Blaauboer 2007; Louisse et al. 2010a; Paini et al. 2010; Verwei et al. 2006a; Rotroff et al. 2010; Wetmore et al. 2012; Strikwold et al. 2013) (Fig. 1). In reverse dosimetry approaches for the prediction of in vivo toxicity dose levels, in vitro effect concentrations are considered as surrogate tissue or blood concentrations that would cause toxicity in the in vivo situation. To predict in vivo toxic dose levels, a PBK model is used to calculate the doses that are needed to reach these surrogate tissue or blood concentrations. By this translation of concentrations into doses, in vitro concentration-response data can be translated into in vivo dose-response data. These data can be used to obtain a point of departure (POD) for
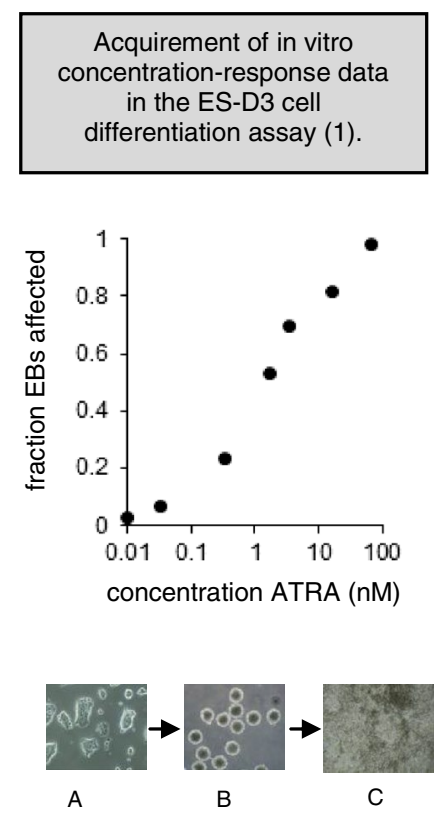

ES-D3 cell differentiation assay: Assessment of chemical-induced inhibition of pluripotent stem cell (A) differentiation into contracting cardiomyocytes $(\mathrm{C})$ via the embryoid body (EB) stage (B). The inhibition of EB differentiation into contracting cardiomyocytes is used as the in vitro developmental toxicity endpoint.

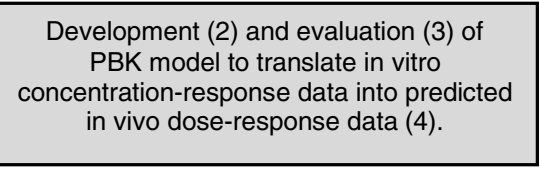

Input: in vitro concentrations

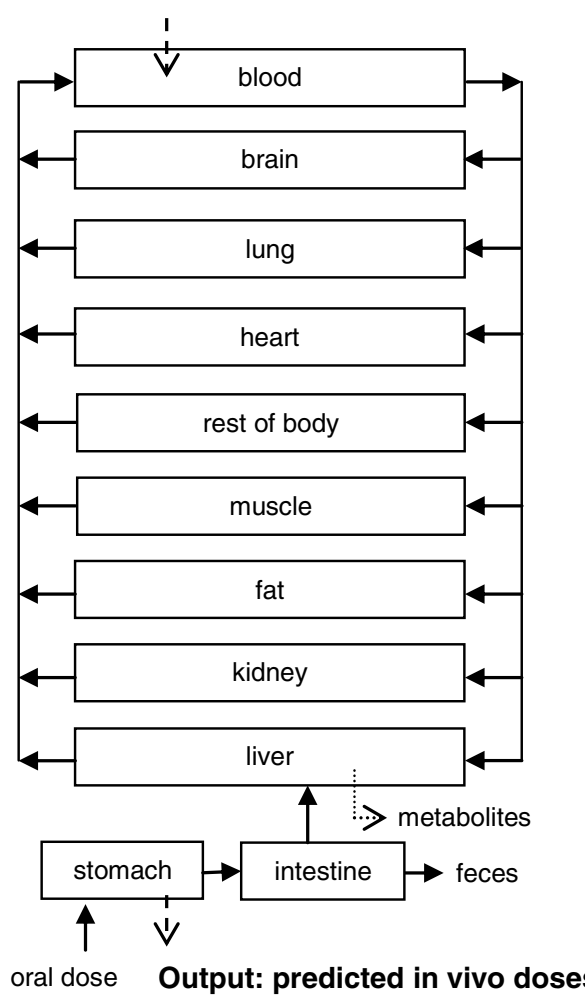

Application of BMD modeling on predicted dose-response data to obtain $\mathrm{BMDL}_{10}$ as POD for risk assessment (5) and evaluation of predictive value of the approach (6).

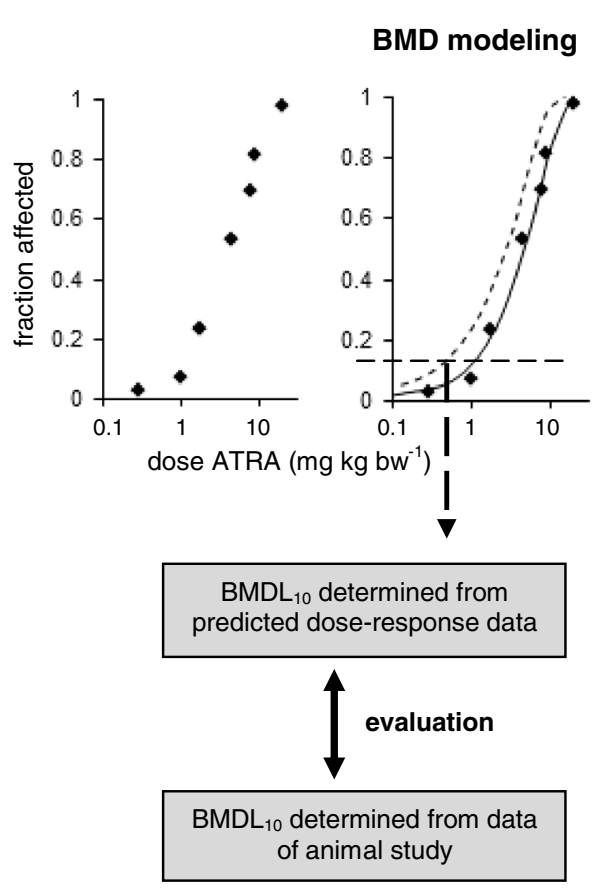

Fig. 1 A schematic representation of the reverse dosimetry approach used in the present study. The in vitro concentration-response data presented were taken from our earlier study (Louisse et al. 2011), whereas the predicted in vitro dose-response data are hypothetical 
risk assessment, like a benchmark dose (BMD). Regarding developmental toxicity, this approach has been used to predict BMDs for a group of glycol ethers (Louisse et al. 2010a) and of phenol (Strikwold et al. 2013), based on the translation of in vitro concentration-response data on the inhibition of embryonic stem (ES-D3) cell differentiation into in vivo dose-response data. To further explore the potential applicability of the reverse dosimetry approach, examples with chemicals from other chemical categories, with different physico-chemical properties and/or specific mechanisms of action, are needed. In addition, PBK models, which are currently often built using in vivo kinetic data (Rietjens et al. 2011), should instead be preferentially based on parameter values obtained using in vitro and/or in silico techniques to increase their contribution to the replacement, reduction and refinement (3Rs) of animal use in toxicity testing.

The aim of the present study was to assess the feasibility of predicting in vivo developmental toxicity dose levels of the developmental toxicant all-trans-retinoic acid (ATRA) with reverse dosimetry, using a PBK model that was based on kinetic parameter values that are derived using mainly in vitro techniques. ATRA was chosen for this study, since the mechanism underlying its toxicity is specific [interfering with endogenous retinoid signaling pathways (Collins and Mao 1999)] and its in vitro effect concentrations are low (Louisse et al. 2011). The results obtained show that $\mathrm{BMDL}_{10}$ values [lower limit of the $95 \%$ confidence interval on the BMD at which a benchmark response equivalent to a $10 \%$ effect size $\left(\mathrm{BMR}_{10}\right)$ is reached $\left(\mathrm{BMD}_{10}\right)$ ] derived from predicted in vivo dose-response data in rat differ about sixfold from $\mathrm{BMDL}_{10}$ values derived from in vivo developmental toxicity data reported in the literature, indicating that the reserve dosimetry approach is promising to derive PODs for risk assessment and therefore to increase the acceptance and implementation of in vitro assays in toxicological risk assessment.

\section{Materials and methods}

\section{Chemicals}

ATRA and taurocholate were purchased from SigmaAldrich (Zwijndrecht, the Netherlands) and $\left[11,12-{ }^{3} \mathrm{H}(\mathrm{N})\right]-$ ATRA, [1-methyl- $\left.{ }^{14} \mathrm{C}\right]$-caffeine and $\mathrm{D}-\left[1-{ }^{3} \mathrm{H}(\mathrm{N})\right]$-mannitol from Perkin-Elmer (Groningen, the Netherlands). Polydimethylsiloxane (PDMS) was obtained from General Electrics Plastics BV (Bergen op Zoom, the Netherlands) and hexane from Biosolve (Valkenswaard, the Netherlands). Ethanol, KOH and HEPES were purchased from Merck Chemicals (Darmstadt, Germany).

\section{Reverse dosimetry approach}

The reverse dosimetry approach we used is depicted schematically in Fig. 1 and consists of six steps, being (1) acquirement of in vitro concentration-response data in the ES-D3 cell differentiation assay, (2) development of a PBK model for ATRA kinetics in rat and human, (3) evaluation of the PBK model, (4) translation of in vitro concentrationresponse data into predicted in vivo dose-response data using the PBK model, (5) application of BMD modeling on predicted dose-response data to obtain a POD for risk assessment and (6) evaluation of the predictive value of the approach.

Acquirement of in vitro concentration-response data in the ES-D3 cell differentiation assay

The in vitro concentration-response data for ATRA were obtained from our earlier study on the effect of retinoids on the inhibition of ES-D3 cell differentiation (Louisse et al. 2011). The data of three independent runs were combined to one dataset, which is presented in Fig. 1.

\section{Development and evaluation of a PBK model for ATRA} kinetics in rat and human

The graphical representation of the PBK model developed for ATRA is shown in Fig. 1. Values for anatomical and physiological parameters are presented in supplementary Tables 1 and 2. Values for rats were taken from Brown et al. (1997). For humans, virtual populations were randomly generated from the NHANES database using PopGen (http://xnet.hsl.gov.uk/popgen/). We used physB (Bosgra et al. 2012) to generate organ weights and blood flows for the populations, as particularly the median weights of liver, kidney and heart generated by PopGen were considered unusually high. We developed two virtual human populations for the present study. The first one was used to simulate the potential interindividual variability in pharmacokinetics of ATRA in the study of Adamson et al. (1993), which contains the data we used for the model evaluation. To this end, a population of 1,000 individuals with $66 \%$ males and $34 \%$ females, age constrained between 44 and 78 years, height constrained between 160 and $190 \mathrm{~cm}$, and body weight with BMI between 18.5 and 25 was generated. The second population was used to simulate the potential interindividual variability in pharmacokinetics of ATRA in the population of interest to determine a POD for risk assessment for developmental toxicity. To this end, a population of 1,000 individuals with $100 \%$ females, age constrained between 16 and 40 years, height constrained between 160 
and $190 \mathrm{~cm}$, and body weight with BMI between 18.5 and 25 was generated.

The processes of stomach emptying [half-life; rat, liquid: $15 \mathrm{~min}$ (Reilly et al. 1990), human, liquid: $15 \mathrm{~min}$ (Sun et al. 1988)] and the small intestinal transition [complete transition; rat: $1.5 \mathrm{~h}$, human: $4 \mathrm{~h}$ (Davies and Morris 1993)] are included in the model. To describe small intestinal transition, the intestinal compartment was divided in 7 sub-compartments over which the chemical transition was described.

Values for chemical-specific kinetic model parameters were determined in the present study. These kinetic parameter values were obtained using data derived using in vitro techniques and include parameter values for (1) intestinal absorption, (2) partitioning into tissues and (3) metabolic clearance. PBK model equations were solved using acslX software (version 3.0.2.1; AEgis Technologies Group).

\section{Determination of model parameter values for intestinal absorption}

The parameter value for intestinal absorption rate was determined by multiplying intestinal apparent permeability $\left(P_{\text {app }}\right)$ coefficients for rat and human by the surface area of the intestine and the luminal concentration in the intestine (Verwei et al. 2006b): absorption rate ATRA $\left(\mu \mathrm{mol} \mathrm{h} \mathrm{h}^{-1}\right)=P_{\text {app }}$ coefficient $\left(\mathrm{cm} \mathrm{h}^{-1}\right) \times$ surface area of small intestine $\left(\mathrm{cm}^{2}\right) \times$ luminal concentration of ATRA (mM).

For the rat model, the $P_{\text {app }}$ coefficient as reported for in situ perfused rat jejunum preparations was used (Zimmerman et al. 2001). For the PBK model, it was assumed that the whole rat small intestine has the same absorption characteristics as this jejunum segment. The value for the small intestine surface area was calculated to be $94 \mathrm{~cm}^{2}$ [radius of $0.18 \mathrm{~cm}$ (Zimmerman et al. 2001) and a small intestine length of $83 \mathrm{~cm}$ (McConnell et al. 2008)]. The surface area in this calculation does not need to include the increased surface area resulting from the presence of macro- and microvilli, since these are already present in the in situ perfused rat jejunum model. The luminal concentration of ATRA is calculated by the model by dividing the amount of ATRA ( $\mu \mathrm{mol})$ by the small intestinal volume $(\mathrm{mL})$. The small intestinal volume was calculated to be $8.4 \mathrm{~mL}$.

For the human model, the $P_{\text {app }}$ coefficient for the human small intestine was estimated based on $P_{\text {app }}$ coefficients obtained in an intestinal transport model consisting of human intestinal colorectal adenocarcinoma (Caco-2) cell layers (Sun et al. 2002). Sun et al. (2002) described the correlation between Caco-2 permeability and human jejunum permeability by: $\log \left(P_{\text {app,jejunum }}\right)=0.7524 \times \log \left(P_{\text {app,Ca }}\right.$ co-2) -0.5441 . Caco-2 transport studies were performed as described below to establish $\mathrm{P}_{\text {app,Caco-2 }}$ which was used to estimate $\mathrm{P}_{\text {app,jejunum. The intestinal absorption rate for }}$ the human PBK model was determined as was done for the rat model using the estimated $P_{\text {app,jejunum }}$, a small intestine surface area of $72 \mathrm{dm}^{2}$ and a small intestinal volume of $9 \mathrm{~L}$ [radius of $2.5 \mathrm{~cm}$ (Kararli 1995) and a small intestine length of $460 \mathrm{~cm}$ (Hosseinpour and Behdad 2008)]. The surface area in this calculation does not need to include the increased surface area resulting from the presence of folding and macro- and microvilli, since these are already present in the in situ perfused human jejunum model.

For the Caco-2 transport studies, Caco-2 cells (P7-P9, obtained from ATCC) were grown on Costar 12-well transwell plate inserts (Corning; membrane pore size: $0.4 \mu \mathrm{m}$, surface area: $1.12 \mathrm{~cm}^{2}$ ) by adding $0.5 \mathrm{~mL}$ of a $2.24 \times 10^{5}$ cell suspension in culture medium [Dulbecco's modified Eagle's medium (DMEM, Invitrogen, Breda, the Netherlands, cat. no. 61965), supplemented with $10 \%$ fetal calf serum (BioWhittaker, Verviers, Belgium), $100 \mu \mathrm{M}$ nonessential amino acids (Invitrogen) and $50 \mu \mathrm{g} \mathrm{mL}^{-1}$ gentamycin (Invitrogen)] to each transwell plate insert (apical compartment) and $1.5 \mathrm{~mL}$ of culture medium to the basolateral compartment. Cells were grown in a humidified atmosphere $\left(5 \% \mathrm{CO}_{2}\right)$ at $37{ }^{\circ} \mathrm{C}$. Culture medium was refreshed every $2-3$ days. Transport studies were performed 20 days post-seeding. Barrier integrity was ensured by transepithelial electrical resistance (TEER) measurements using a Millicell ERS-2 Voltohmmeter (Millipore, USA), showing TEER values of $\sim 500 \Omega \mathrm{cm}^{2}$. To mimic typical in vivo conditions, ATRA's transport characteristics were studied in the in vitro system using $10 \mathrm{mM}$ taurocholate (to mimic intestinal bile acid concentration) in the apical compartment and $0.6 \mathrm{mM}$ BSA (Sigma-Aldrich) (to mimic blood albumin concentration) in the basolateral compartment. For transport studies, the apical compartment was filled at $t=0$ with $0.65 \mathrm{~mL} 10 \mathrm{mM}$ 4-(2-hydroxyethyl)-1-piperazineethanesulfonic acid (HEPES) in Hank's balanced salt solution (HBSS, Invitrogen) ( $\mathrm{pH}$ 6.5) containing the test chemicals $\left[\left[11,12-{ }^{3} \mathrm{H}(\mathrm{N})\right]\right.$-ATRA $(1,10,100,1000$ or $10000 \mathrm{nM})$, [1-methyl- $\left.{ }^{14} \mathrm{C}\right]$-caffeine $(10 \mu \mathrm{M})$ (control for transcellular transport) or $\mathrm{D}-\left[1-{ }^{3} \mathrm{H}(\mathrm{N})\right]-$ mannitol $(10 \mu \mathrm{M})$ (control for paracellular transport)] supplemented with $10 \mathrm{mM}$ taurocholate. The basolateral compartment was filled with $1.5 \mathrm{~mL}$ HBSS (pH 7.4) supplemented with $0.6 \mathrm{mM}$ BSA (Sigma-Aldrich). Initial experiments using varying incubation times showed that transport velocity was linear until $\sim 30 \mathrm{~min}$. For the final transport studies, a sample from the apical compartment $(0.15 \mathrm{~mL})$ was taken at $t=0$ to determine the start concentration, leaving an apical volume of $0.5 \mathrm{~mL}$ during the transport study. At $t=10 \mathrm{~min}$, a sample from the basolateral compartment $(0.5 \mathrm{~mL})$ was taken followed by the addition of $0.5 \mathrm{~mL}$ HBSS (supplemented with $0.6 \mathrm{mM} \mathrm{BSA}$ ) to retain a volume of $1.5 \mathrm{~mL}$. At $t=20 \mathrm{~min}$, samples were taken from the apical $(0.15 \mathrm{~mL})$ and the 
basolateral $(0.5 \mathrm{~mL})$ compartments, after which the transwell filters with cells were washed with HBSS and incubated in $0.5 \mathrm{~mL} 80 \% 1.5 \mathrm{M} \mathrm{KOH} / 20 \%$ ethanol. Radioactivity was measured after adding $10 \mathrm{~mL}$ of OptiPhase HiSafe (Perkin-Elmer) to the apical and basolateral samples and the filters with cells, using a Tri-Carb Liquid Scintillation Counter (Perkin-Elmer). The calculated amounts in the three compartments (apical compartment, basolateral compartment and filter plus cells) were used for mass balance calculations.

\section{Determination of model parameters values for tissue/blood partitioning}

Tissue/blood partition coefficients were calculated by dividing tissue/buffer (PBS, Invitrogen) partition coefficients by blood/buffer partition coefficients. The tissue/ buffer and blood/buffer partition coefficients were determined using a recently developed solid-phase microextraction (SPME)-based approach developed by the Netherlands Organization for Applied Scientific Research (TNO, Zeist, the Netherlands) (Vaes 2010). In this approach, the chemical of interest is able to distribute over three phases (compartments), which are (1) a buffer phase, (2) a serum (or tissue homogenate) phase and (3) a coating phase. It is assumed that the chemical will distribute over these phases according to the following equation:

$M_{\mathrm{t}}=C_{\mathrm{b}} \times V_{\mathrm{b}}+C_{\mathrm{s}} \times V_{\mathrm{s}}+C_{\mathrm{c}} \times V_{\mathrm{c}}$

in which $M_{\mathrm{t}}$ total mass, $C_{\mathrm{b}}$ concentration in buffer, $V_{\mathrm{b}}$ volume buffer, $C_{\mathrm{s}}$ concentration in serum (or tissue homogenate), $V_{\mathrm{s}}$ volume serum (or tissue homogenate), $C_{\mathrm{c}}$ concentration in coating and $V_{\mathrm{c}}$ volume coating. The concentration of the chemical in the coating can be described as:

$C_{\mathrm{c}}=C_{\mathrm{b}} \times K_{\mathrm{c}}$

in which $C_{\mathrm{c}}$ concentration in coating, $C_{\mathrm{b}}$ concentration in buffer and $K_{\mathrm{c}}$ coating/buffer partition coefficient. The concentration of the chemical in the serum can be described as:

$C_{\mathrm{s}}=C_{\mathrm{b}} \times K_{s}$

in which $C_{\mathrm{s}}$ concentration in serum (or tissue homogenate), $C_{\mathrm{b}}$ concentration in buffer and $K_{\mathrm{s}}$ serum (or tissue homogenate)/buffer partition coefficient.

These equations can be rewritten as:

$A_{\mathrm{c}}=M_{\mathrm{t}} /\left(1+\left(\left(V_{\mathrm{b}}+K_{\mathrm{s}} \times V_{\mathrm{s}}\right) /\left(V_{\mathrm{c}} \times K_{c}\right)\right)\right)$

in which $A_{\mathrm{c}}$ amount in coating, $M_{\mathrm{t}}$ total mass, $V_{\mathrm{b}}$ volume buffer, $K_{\mathrm{s}}$ serum (or tissue homogenate)/buffer partition coefficient, $V_{\mathrm{s}}$ volume serum (or tissue homogenate), $V_{\mathrm{c}}$ volume coating and $K_{\mathrm{c}}$ coating/buffer partition coefficient.

In the experimental set-up, 96-well plates [Flexible 96, Clear 96-well Flexible PET microplates, round bottom
(Perkin-Elmer)] were coated with varying volumes of PDMS $\left(V_{c}\right)$. This was achieved by adding $200 \mu \mathrm{L}$ of varying PDMS concentrations dissolved in hexane to the wells, after which the hexane was allowed to evaporate. Varying concentrations of serum (Sigma) [or tissue homogenates (tissues obtained from a 2-month-old male Wistar rat)], obtained by dilution in buffer, were spiked with $\left[11,12-{ }^{3} \mathrm{H}(\mathrm{N})\right]-A T R A$, after which $200 \mu \mathrm{L}$ of these solutions were added per (coated) well. The serum (or tissue homogenate) concentration can be described as a volume of serum and a volume of buffer (together amounting to $200 \mu \mathrm{L}$ ) resulting in varying serum (or tissue homogenates) volumes $\left(V_{\mathrm{s}}\right)$ and buffer volumes $\left(V_{\mathrm{b}}\right)$. Per 96-well plate, a maximum of 96 situations can be created with different combinations of $V_{\mathrm{c}}, V_{\mathrm{b}}$ and $V_{\mathrm{s}}$. Plates are placed overnight at an orbital shaker to allow equilibration of the chemical over the different phases. Subsequently, per well, $50 \mu \mathrm{L}$ of the medium was removed from the wells and transferred to a non-coated 96-well plate, and the remaining medium from the coated 96-well plate was removed and the plate was washed. To both plates, $200 \mu \mathrm{L}$ of OptiPhase HiSafe was added per well, after which the plates were covered with TopSeal ${ }^{\circledR}$-A: 96-well microplate press-on adhesive sealing film (Perkin-Elmer). Radioactivity measurements were performed using a 1450-023 MicroBeta TriLux Microplate Scintillation and Luminescence Counter (Perkin-Elmer) to obtain $\mathrm{A}_{\mathrm{c}}$ (radioactivity in coating) and $\mathrm{M}_{\mathrm{t}}$ [radioactivity in coating + radioactivity of transferred medium (times four, because one-fourth of medium is used for radioactivity counting of medium)]. In Eq. $4, V_{\mathrm{b}}, V_{\mathrm{s}}$ and $V_{\mathrm{c}}$ are experimental variables and $A_{\mathrm{c}}$ and $M_{\mathrm{t}}$ are determined by radioactivity measurements. The two remaining unknowns, $K_{\mathrm{s}}$ and $K_{\mathrm{c}}$, are obtained by nonlinear least squares fitting of Eq. 4 to the dataset of 96 different combinations of $V_{\mathrm{b}}, V_{\mathrm{s}}$ and $V_{\mathrm{c}}$. The free fraction in pure serum (or tissue homogenate) can be obtained by using the $K_{\mathrm{s}}$ [free fraction $\left.=1 /\left(K_{\mathrm{s}}+1\right)\right]$. For calculation of the blood/buffer partition coefficient, it was assumed that ATRA only binds to serum components in blood, assuming that blood consists of two-third of plasma (Lee and Blaufox 1985), implicating that pure blood was considered as 1.5 times diluted plasma.

\section{Determination of model parameters values for metabolic clearance}

Data on the in vitro kinetic conversion of ATRA by microsomes or specific biotransformation enzymes as reported in the literature (Ahmad et al. 2000; Little et al. 1997; Thatcher et al. 2010; Lutz et al. 2009; Samokyszyn et al. 2000; supplementary Table 3) were used to determine the model parameter values for hepatic clearance. For the rat model, kinetic constants on ATRA metabolism obtained 
using liver, kidney, lung and brain fractions were used, whereas for the human model, kinetic constants on ATRA metabolism obtained using specific cytochrome P450 (CYP) and uridine 5'-diphospho-glucuronosyltransferase (UGT) enzymes were used (supplementary Table 3). The reported apparent $K_{\mathrm{m}}$ values were applied in the PBK model, whereas the apparent $V_{\max }$ values were scaled to a complete organ using a microsomal protein per gram of liver (MPPGL) of $35 \mathrm{mg}$ for rat liver (Medinsky et al. 1994), a MPPGK of $7 \mathrm{mg}$ for rat kidney (Beierschmitt and Weiner 1986), a MPPGLu of $20 \mathrm{mg}$ for rat lung (Medinsky et al. 1994), a MPPGB of $4 \mathrm{mg}$ for rat brain (Ravindranath and Anandatheerthavarada 1990), and a MPPGL for human liver as generated by PopGen (supplementary Table 2).

Variation in expression levels of the CYP and UGT enzymes per gram microsomal protein in the human liver has been reported in the literature and was included in the model. UGT2B7 levels have been reported for 8 adult liver samples (Zaya et al. 2006), with a geometric mean (GM) of 0.045 and a geometric standard deviation (GSD) of $1.56 \mu \mathrm{g}$ mg microsomal protein ${ }^{-1}$. CYP3A7 abundance was found above detection limit in only 6 out of 59 liver samples (Sim et al. 2005), ranging from 24 to 90 pmol mg microsomal protein $^{-1}$. CYP26A1 has been identified in $70 \%$ of 37 donors (Thatcher et al. 2010), with a GM of 1.47 and an estimated GSD of $1.25 \mathrm{pmol} \mathrm{mg}$ microsomal protein $^{-1}$. The abundance of CYP2C8 was reported for liver samples of 60 individuals (29 males, 31 females) (Naraharisetti et al. 2010). Hepatic CYP3A4 and CYP3A5 contents were reported in 60 individuals of unreported gender genotyped for CYP3A5*1/*1, *1/*3 and *3/*3 (Lin et al. 2002). These genotypes were found to occur in the American population with frequencies of $0.08,0.29$ and 0.63 , respectively, with no significant difference between males and females (Kharasch et al. 2007). Expression of hepatic CYP3A4 was found to be around a factor two higher in females than in males (Wolbold et al. 2003).

A combination of parametric and nonparametric random sampling was used to assign hepatic enzyme levels to the simulated population. First, CYP3A5 genotypes were randomly assigned to the 1,000 individuals with the probabilities mentioned above. Then, combinations of CYP3A4 and CYP3A5 of the appropriate CYP3A5 genotype were randomly drawn (with replacement) from the dataset of Lin et al. (2002), conditionally sampling CYP3A4 content below 120 pmol mg microsomal protein $^{-1}$ for males and above 60 pmol mg microsomal protein $^{-1}$ for females. As only one measurement of CYP3A abundance in CYP3A $5 * 1 / * 1$ genotype was available, the CYP3A5 content for individuals of this genotype was fixed at the reported 289 pmol mg microsomal protein ${ }^{-1}$, while CYP3A4 content was drawn randomly and sex-dependently from all available data. This procedure maintains the distributions of and correlations between CYP3A4 and 3A5 in the dataset and ensures a sexual bimodality in CYP3A4 content (with medians of 46 and $102 \mathrm{pmol} \mathrm{mg}^{-1}$ for males and females, respectively). Last, we assigned to the individuals enzyme levels of UGT2B7 from a lognormal distribution, of CYP3A7 from the 6 measured levels and 54 zero's, of CYP2C8 from the 60 samples, and of CYP26A1 from a lognormal distribution for $70 \%$ and zero's for $30 \%$.

\section{PBK model evaluation}

For the model evaluation, we performed a global sensitivity analysis using a Morris test, which is preferred above a local sensitivity analysis, which may lead to misleading results when there are substantial interactions among multiple parameters (like with PBK models) (McNally et al. 2011). The Morris test produces two sensitivity parameters for each PBK model parameter, which are $\mu$ and $\sigma$. A high $\mu$ indicates a parameter with an overall influence on model output, whereas a high $\sigma$ indicates a parameter interacting with other parameters, or a parameter with nonlinear effects (McNally et al. 2011). A Morris test was performed for the blood concentration at $1.5 \mathrm{~h}$ (around $T_{\max }$ ) and area under the blood concentration-time (AUC) curve between 0 and $24 \mathrm{~h}$ following an oral dose of $0.1 \mathrm{mg} \mathrm{kg} \mathrm{bw}^{-1}$ in rats and $2 \mathrm{mg} \mathrm{kg} \mathrm{bw}{ }^{-1}$ in human to identify an approximate rank order of most sensitive model parameters. Plausible ranges for rat parameter values were defined as a factor between the median and 5th and 95th percentiles. The $P_{\text {app }}$ and $V_{\max }$ values of hepatic metabolism were considered most uncertain with a factor 2 (including uncertainty in in vitro-in vivo scale-up). $K_{\mathrm{m}}$ values of hepatic metabolism and partition coefficients were varied by a factor 1.5 and anatomical/ physiological parameters were varied by a factor 1.1. For the human PBK model, the parameters listed in supplementary Table 2 were allowed to vary between 5 th and 95th percentiles. The plausible ranges of the remaining parameters were defined as in the Morris screening for the rat model.

In order to assess how the PBK model performs in predicting ATRA plasma concentrations in rats and humans, the predicted ATRA plasma concentrations were compared with plasma concentrations from in vivo kinetic studies as reported in the literature (Swanson et al. 1981; Shelley et al. 1982; El Mansouri et al. 1995; Collins et al. 1995; Adamson et al. 1993; supplementary Table 4). These kinetic data have not been used to optimize model performance, but have solely been used for model evaluation.

Translation of in vitro concentration-response data into predicted in vivo dose-response data

In the reverse dosimetry approach for the prediction of in vivo developmental toxicity dose levels, the in vitro effect 
concentrations of the ES-D3 cell differentiation assay are considered as surrogate in vivo blood concentrations that would result in the perturbation of embryonic development. Since ATRA has a high binding affinity for proteins and lipids (Smith et al. 1973), differences are expected in the free fraction of ATRA in vitro (culture medium) compared with in vivo (blood) (Gülden et al. 2006; Blaauboer 2010). Because it is assumed that the free fraction of the chemical will cause the toxicity, corrections were made to take the differences in the free fraction in the in vitro compared with the in vivo situation into account. To this end, the culture medium/buffer and blood/buffer partition coefficients $\left(K_{\mathrm{s}}\right)$ were determined using the SPME-based approach as described before, to calculate the free fraction in vitro and in vivo [free fraction $=1$ / $\left.\left(K_{\mathrm{s}}+1\right)\right]$. Translation of the in vitro concentrations into in vivo doses was made by relating the toxic effect (both in vitro and in vivo) to the maximum concentration $\left(C_{\max }\right)$ or to the AUC. To relate the toxic effect to the AUC, the concentration-response data were translated to AUC-response data, by multiplying the applied concentration with the assay time (Daston et al. 2010). Subsequently, we assessed which oral doses are required in the PBK model to reach the effect concentrations $\left(C_{\max }\right.$ or AUC) of ATRA-induced inhibition of ES-D3 cell differentiation. By performing this exercise for each concentration (or AUC) used in the in vitro assay, all in vitro concentration-response data (or AUC-response data) were translated into predicted in vivo dose-response data.

Application of BMD modeling on predicted dose-response data to obtain a POD for risk assessment

BMD modeling was applied on the predicted in vivo doseresponse data using all models for dichotomous data of the Environmental Protection Agency (EPA)'s Benchmark Dose Software (BMDS) version 2.4. All models that met the requirements for acceptance of model fit were considered for the determination of $\mathrm{BMDL}_{10}$ values. The lowest obtained BMDL $_{10}$ value was used for comparison of BMDL ${ }_{10}$ values derived from predicted dose-response data with $\mathrm{BMDL}_{10}$ values derived from in vivo dose-response data.

Evaluation of the predictive value of the approach

To evaluate the potential of the in vitro-in silico approach to obtain a POD for risk assessment, the predicted $\mathrm{BMDL}_{10}$ values for rat were compared with $\mathrm{BMDL}_{10}$ values derived from data of rat developmental toxicity studies reported in the literature (Bürgin and Schmitt 2003; Wise et al. 2010). $\mathrm{BMDL}_{10}$ values for these studies were determined using the reported data on malformations (the most sensitive reported malformation endpoint was chosen), using EPA's BMDS version 2.4. All models that met the requirements for acceptance of model fit were considered for the determination of $\mathrm{BMDL}_{10}$ values. The lowest obtained $\mathrm{BMDL}_{10}$ value was used for comparison of $\mathrm{BMDL}_{10}$ values derived from predicted dose-response data with $\mathrm{BMDL}_{10}$ values derived from in vivo dose-response data.

\section{Results}

Development of a PBK model for ATRA kinetics in rat and human

The PBK model code is presented in the supplementary materials.

\section{Parameter value for intestinal absorption}

The parameter values for the intestinal absorption rate were determined by multiplying $P_{\text {app }}$ coefficients for rat and human intestinal absorption by the surface area of the intestine and the luminal concentration in the intestine (see "Materials and methods" for calculations). The $P_{\text {app }}$ coefficient for the rat intestines was taken from Zimmerman et al. (2001), being $73 \times 10^{-6} \mathrm{~cm} \mathrm{~s}^{-1}$ (equivalent to $0.26 \mathrm{~cm} \mathrm{~h}^{-1}$ ). The $P_{\text {app }}$ coefficient for human intestines was estimated based on $P_{\text {app }}$ coefficients obtained in Caco-2 transport studies. The obtained $P_{\text {app }}$ coefficient using 1, 10, $100,1,000$ or $10,000 \mathrm{nM}$ ATRA did not depend on the concentration applied. Therefore, the average $P_{\text {app }}$ coefficient $\left(18 \times 10^{-6} \mathrm{~cm} \mathrm{~s}^{-1}\right.$ equivalent to $\left.0.065 \mathrm{~cm} \mathrm{~h}^{-1}\right)$ was used to estimate human intestinal permeability, applying the formula reported by Sun et al. (2002), resulting in a $P_{\text {app }}$ coefficient of $77 \times 10^{-6} \mathrm{~cm} \mathrm{~s}^{-1}$ (equivalent to $0.28 \mathrm{~cm} \mathrm{~h}^{-1}$ ).

\section{Parameter values for tissue/blood partition coefficients}

Table 1 shows the tissue/buffer partition coefficients (with olive oil representing fat tissue) and the tissue/blood

Table 1 Rat tissue/buffer partition coefficients and rat tissue/blood partition coefficients

\begin{tabular}{lll}
\hline & $\begin{array}{l}\text { Tissue/buffer partition } \\
\text { coefficient }\end{array}$ & $\begin{array}{l}\text { Tissue/blood partition } \\
\text { coefficient }^{\mathrm{a}}\end{array}$ \\
\hline Olive oil (fat) & 2,200 & 6.8 \\
Lung & 1,280 & 3.9 \\
Brain & 4,460 & 14 \\
Heart & 640 & 2.0 \\
Kidney & 1,810 & 5.6 \\
Muscle & 1,120 & 3.5 \\
Liver & 1,160 & 3.6 \\
\hline
\end{tabular}

a Tissue/blood partition coefficients were calculated by dividing tissue/buffer partition coefficients by the blood/buffer partition coefficients (which amounted to 325 ) 
partition coefficients, which were obtained by dividing the tissue/buffer partition coefficients by the blood/buffer partition coefficient (measured to be 325). The rest-of-body/ blood partition coefficient in the model was set at 1 . The tissue/blood partition coefficients determined for rat were also used for the human PBK model.

\section{PBK model evaluation}

Figure 2 shows the most sensitive parameters resulting from the Morris screening test. It shows that the predictions of $C_{\max }$ (Fig. 2a) and AUC (Fig. 2b) in the rat model are most sensitive to the intestinal absorption $\left(P_{\text {app }}\right)$, the maximal velocity of hepatic ATRA oxidation $\left(V_{\text {max } \_ \text {ox }}\right)$ and the blood/muscle partition coefficient $\left(P_{\mathrm{M}}\right)$. The predictions of $C_{\max }$ (Fig. 2c) and AUC (Fig. 2d) in the human model are most sensitive to the intestinal absorption $\left(P_{\text {app }}\right)$, the MPPGL and the CYP3A5 content per gram microsomal protein (CYP3A5).

To evaluate whether the PBK model, which was developed without the use of in vivo data, was able to predict in vivo kinetics, predicted ATRA plasma concentrations were compared with ATRA plasma concentrations from reported in vivo kinetic studies (Figs. 3, 4; supplementary Table 4). Figure 3 shows in vivo plasma concentrations in rat, as reported in the literature, upon intravenous $(\mathrm{a}-\mathrm{c})$ or oral $(\mathrm{d}-\mathrm{f})$ exposure, together with the PBK model-predicted plasma concentrations. Generally, the PBK model seems
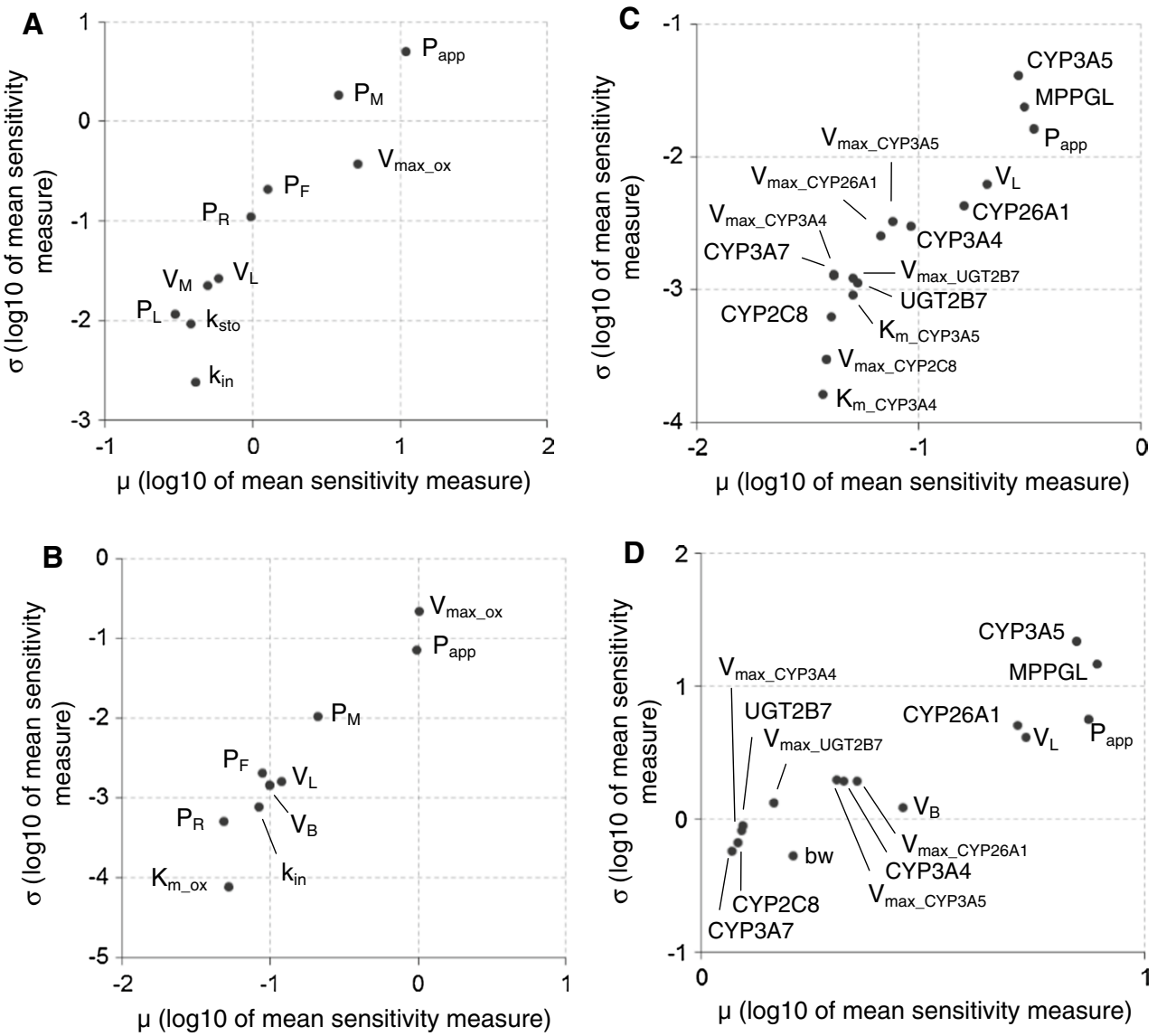

Fig. 2 Results of Morris test for rat (a, b) and human (c, d) for ATRA blood $\mathrm{C}_{\max }$ values $(\mathbf{a}, \mathbf{c})$ and $\mathrm{AUC}$ values $(\mathbf{b}, \mathbf{d})$. bw $=$ body weight, $\mathrm{CYP} 2 \mathrm{C} 8=$ pmol $\mathrm{CYP} 2 \mathrm{C} 8 \mathrm{mg}$ microsomal protein $^{-1}$, CYP3A4 $=$ pmol CYP3A4 mg microsomal protein $^{-1}$, CYP3A5 $=$ pmol CYP3A5 mg microsomal protein $^{-1}$, CYP3A7 $=$ pmol CYP3A7 mg microsomal protein ${ }^{-1}$, CYP26A1 = pmol CYP26A1 mg microsomal $\operatorname{protein}^{-1}, K_{\mathrm{m} \_ \text {ox }}=K_{\mathrm{m}}$ oxidation in rat liver, $K_{\mathrm{m} \_3 \mathrm{~A} 4}=K_{\mathrm{m}}$ oxidation CYP3A4 in human liver, $K_{\mathrm{m} \_3 \mathrm{~A} 5}=K_{\mathrm{m}}$ oxidation CYP3A5 in human liver, $k_{\text {in }}=$ intestinal transition rate, $k_{\text {sto }}=$ stomach emptying rate, MPPGL $=$ microsomal protein per gram of liver, $P_{\text {app }}=P_{\text {app }}$ value (intestinal absorption),

$P_{\mathrm{F}}=$ partition coefficient fat/blood, $P_{\mathrm{L}}=$ partition coefficient liver/ blood, $P_{\mathrm{M}}=$ partition coefficient muscle/blood, $P_{\mathrm{R}}=$ partition coefficient rest-of-body/blood, UGT2B7 $=\mu \mathrm{g}$ UGT2B7 mg microsomal protein $^{-1}, V_{\mathrm{B}}=$ volume blood compartment, $V_{\mathrm{L}}=$ volume liver compartment, $V_{\text {max } \_ \text {ox }}=V_{\max }$ oxidation in rat liver, $V_{\text {max_CYP2C8 }}=V_{\max }$ oxidation CYP2C8 in human liver, $V_{\text {max }}$ CYP3A4 $=V_{\max }$ oxidation CYP3A4 in human liver, $V_{\max \text { CYP3A5 }}=V_{\max }$ oxidation CYP3A5 in human liver, $V_{\text {max }}$ CYP26A1 $=V_{\max }$ oxidation CYP26A1 in human liver, $V_{\text {max_UGT2B7 }}=V_{\max }$ glucuronidation UGT2B7 in human liver, $V_{\mathrm{M}}=$ volume muscle compartment 
Fig. 3 Rat PBK model evaluation by comparison of PBK model-based predicted and literature data on ATRA plasma concentrations in rats after intravenous $(\mathbf{a}-\mathbf{c})$ or oral $(\mathbf{d}-\mathbf{f})$ exposure. Symbols represent average plasma levels (standard deviations are depicted by error bars) from in vivo studies reported in the literature (for references see Supplementary Table 4). Lines represent modelpredicted plasma concentrations. ATRA dose levels for the different curves were a 0.015 (filled circle, solid line), 0.25 (open circle, dashed line) or 5 (filled triangle, dotted line) $\mathrm{mg} \mathrm{kg} \mathrm{bw}{ }^{-1}$; b 2.8 (filled circle, solid line), 6.9 (open circle, dashed line) or 14 (filled triangle, dotted line) $\mathrm{mg} \mathrm{kg} \mathrm{bw}^{-1}$; $8 \mathrm{mg} \mathrm{kg} \mathrm{bw}{ }^{-1} ; \mathbf{d} 6 \mathrm{mg} \mathrm{kg} \mathrm{bw}^{-1}$. e $14 \mathrm{mg} \mathrm{kg} \mathrm{bw}^{-1}$; f $20 \mathrm{mg} \mathrm{kg}$ $\mathrm{bw}^{-1}$
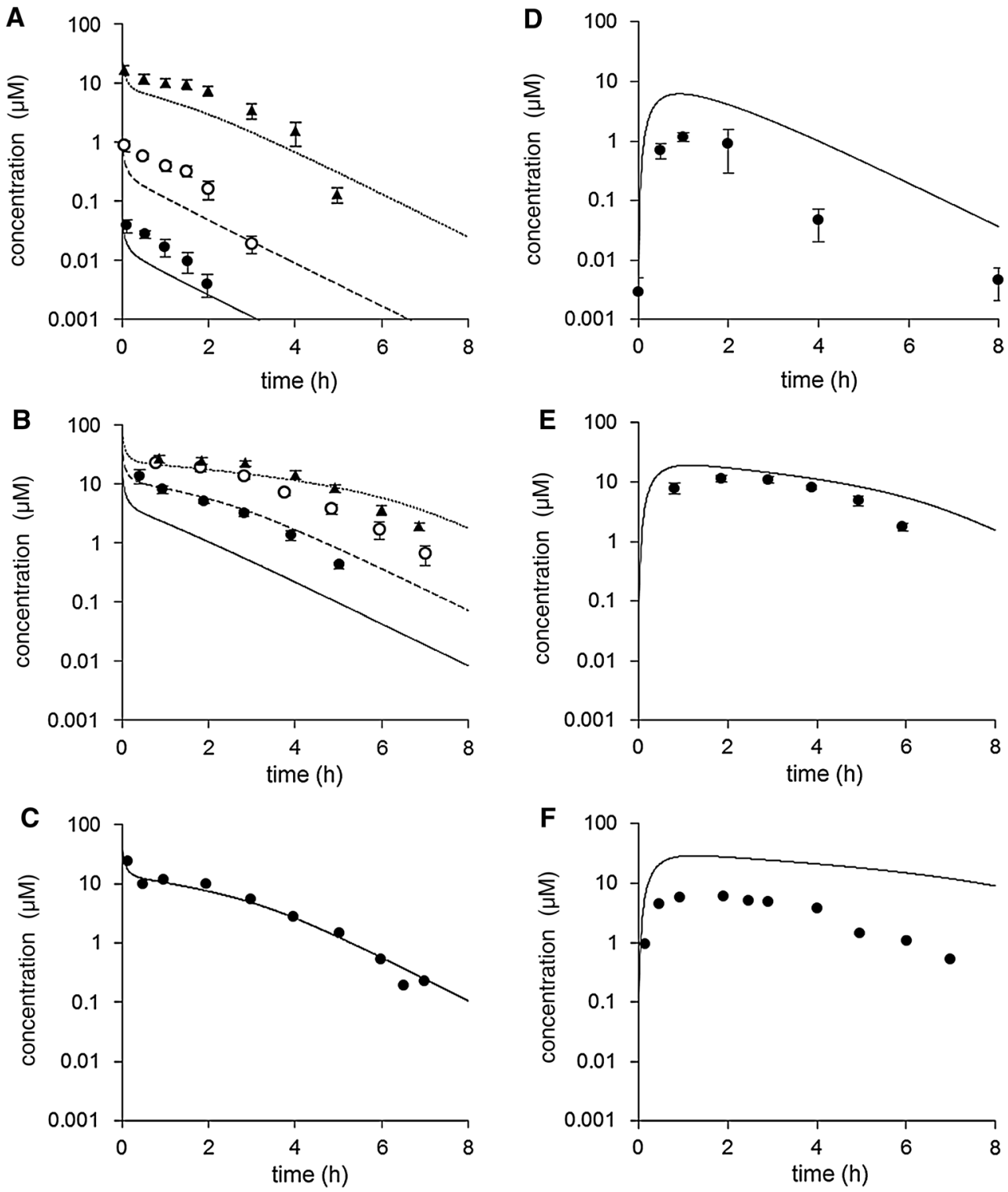

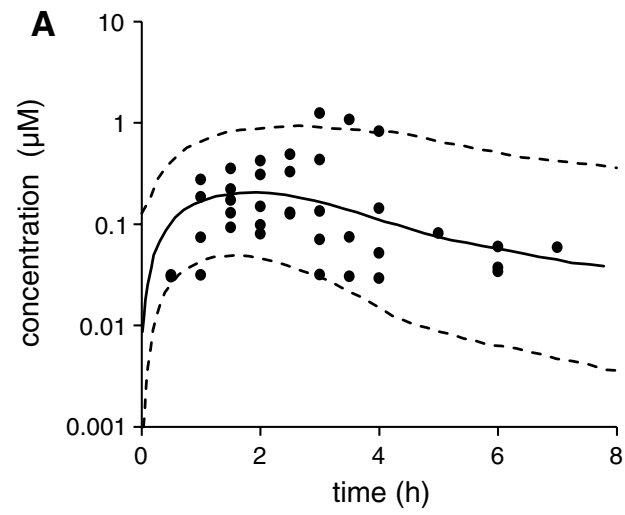

Fig. 4 Human PBK model evaluation by comparison of PBK modelbased predicted and literature data on ATRA plasma concentrations in humans after oral exposure to $2 \mathrm{mg} \mathrm{kg} \mathrm{bw}^{-1}$ (a) or $4 \mathrm{mg} \mathrm{kg} \mathrm{bw}^{-1}$ (b) ATRA. Circles represent plasma concentrations from individuals

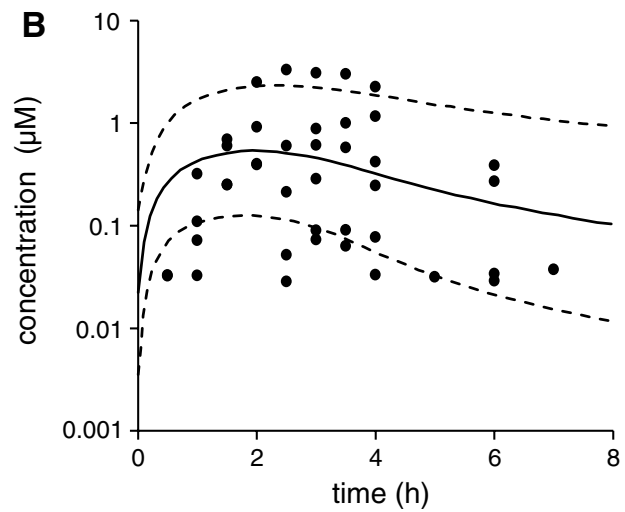

reported by Adamson et al. (1993). Curves represent median (solid line), and the 5th and 95th percentiles (dashed line) of plasma concentrations predicted by the model for the simulated population 
Fig. 5 Dose-response data for developmental toxicity of ATRA in rats, including dose-response curves obtained with BMDS. a, b Predicted dose-response data based on reverse dosimetry; c, d in vivo dose-response data as reported in the literature (Bürgin and Schmitt 2003; Wise et al. 2010). Predicted dose-response data were based on relating the toxic effect to $\mathrm{C}_{\max }$ values (a) or AUC values (b). Dose-response curves are shown for models that met the criteria for model fit (see supplementary materials) and that rendered the lowest $\mathrm{BMDL}_{10}$ value. The $\mathrm{BMD}_{10}$ and $\mathrm{BMDL}_{10}$ values obtained from these dose-response curves are presented in Table 2
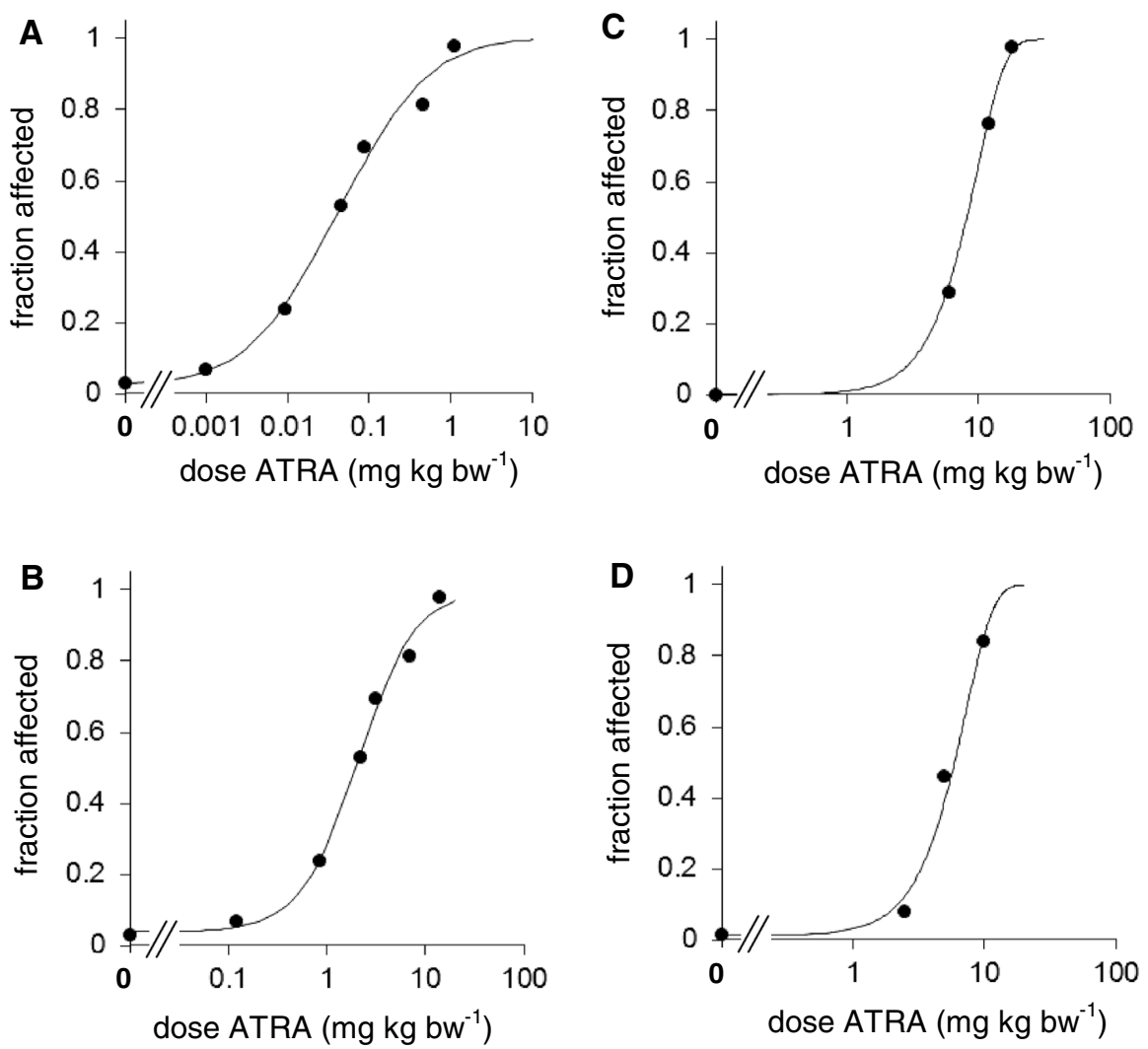

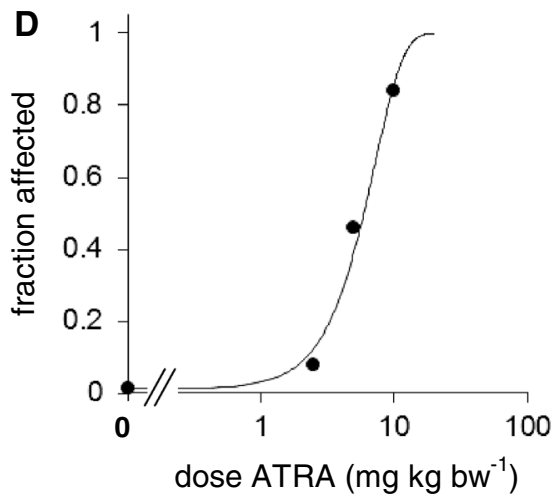

to underpredict ATRA plasma levels upon intravenous exposure and overpredict ATRA plasma levels upon oral exposure, with all deviations within an order of magnitude. Figure 4 shows the human PBK model-predicted ATRA plasma concentrations for the simulated population representing the potential interindividual variability in pharmacokinetics of ATRA in the study of Adamson et al. (1993), as well as the ATRA plasma concentrations in humans as reported in that study. Generally, the PBK model-predicted ATRA plasma concentrations fitted well to the in vivo data reported by Adamson et al. (1993), although certain individuals of the in vivo dataset are outside the predicted 95th percentile of the population, especially at the high dose (Fig. 4).

Translation of the in vitro concentration-response data into predicted in vivo dose-response data, application of BMD modeling on predicted dose-response data, and evaluation of the predictive value of the approach

The free fraction of ATRA in culture medium was calculated to be 3.5 times higher than in rat blood and 6.0 times higher than in human blood. These differences were accounted for when we applied reverse dosimetry. Figure 5 shows predicted dose-response data for rat by applying reverse dosimetry based on the $C_{\max }$ (Fig. 5a) or the
AUC (Fig. 5b) of ATRA in the blood, as well as the doseresponse data for the most sensitive malformation endpoints reported by Bürgin and Schmitt (2003) (Fig. 5c) and Wise et al. (2010) (Fig. 5d). BMD modeling was applied on these datasets (see supplementary Tables 5-12) and models that met the criteria for model fit were considered for $\mathrm{BMD}_{10}$ and $\mathrm{BMDL}_{10}$ determination. The data on the lowest obtained $\mathrm{BMDL}_{10}$ values are presented in Table 2. The dose-response curves of which these $\mathrm{BMD}_{10}$ and $\mathrm{BMDL}_{10}$ values were derived are also presented in Fig. 5.

For the evaluation of the predictive value of the approach, the predicted $\mathrm{BMDL}_{10}$ values for rat were compared with $\mathrm{BMDL}_{10}$ values derived from the in vivo developmental toxicity data reported by Bürgin and Schmitt (2003) and Wise et al. (2010). The predicted BMDL ${ }_{10}$ values for rats were in better concordance with $\mathrm{BMDL}_{10}$ values obtained from the in vivo data when the toxic effect was related to the AUC than when the toxic effect was related to the $C_{\max }$ (Table 2). The $\mathrm{BMDL}_{10}$ value that was derived from the predicted dose-response data (based on the AUC) differed between sixfold and sevenfold from the $\mathrm{BMDL}_{10}$ values that were derived from the in vivo data.

As predictions for rat were better when relating the toxic effect to the AUC, predictions for humans were based on in vitro AUC-response data as well. Since the human model describes variation of ATRA pharmacokinetics in 
Table $2 \mathrm{BMD}_{10}$ and $\mathrm{BMDL}_{10}$ values $\left(\mathrm{mg} \mathrm{kg} \mathrm{bw}^{-1}\right)$ derived from predicted in vivo dose-response data for rat and from in vivo data in rats as reported by Bürgin and Schmitt (2003) and Wise et al. (2010)

\begin{tabular}{|c|c|c|c|c|c|c|c|}
\hline \multicolumn{2}{|c|}{$\begin{array}{l}\text { Predicted dose-response data based } \\
\text { on } C_{\max }\end{array}$} & \multicolumn{2}{|c|}{$\begin{array}{l}\text { Predicted dose-response data based } \\
\text { on AUC }\end{array}$} & \multicolumn{2}{|c|}{ Malformations skull } & \multicolumn{2}{|c|}{$\begin{array}{l}\text { Malformations torso and } \\
\text { limbs }\end{array}$} \\
\hline $\mathrm{BMD}_{10}$ & $\mathrm{BMDL}_{10}$ & $\mathrm{BMD}_{10}$ & $\mathrm{BMDL}_{10}$ & $\mathrm{BMD}_{10}$ & $\mathrm{BMDL}_{10}$ & $\mathrm{BMD}_{10}$ & $\mathrm{BMDL}_{10}$ \\
\hline 0.0030 & 0.0015 & 0.48 & 0.28 & 3.2 & 2.0 & 2.3 & 1.7 \\
\hline
\end{tabular}

Results of full BMD analysis are presented in the supplementary data

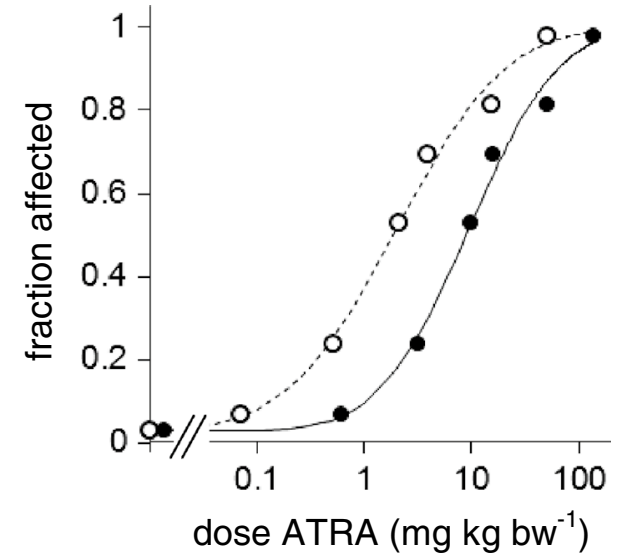

Fig. 6 Predicted dose-response data for developmental toxicity of ATRA in humans based on reverse dosimetry relating the toxic effect to the AUC, including dose-response curves obtained with BMDS. Dose-response data and curves are presented for the median (filled circle, solid line) and the 5th percentile (open circle, thin line) of the simulated population. Dose-response curves are shown for models that met the criteria for model fit (see supplementary materials) and that rendered the lowest $\mathrm{BMDL}_{10}$ value. $\mathrm{BMD}_{10}$ and $\mathrm{BMDL}_{10}$ values are presented in Table 3

Table $3 \mathrm{BMD}_{10}$ and $\mathrm{BMDL}_{10}$ values $\left(\mathrm{mg} \mathrm{kg} \mathrm{bw}^{-1}\right)$ derived from predicted in vivo dose-response data for human for the median and the 5 th percentile of the simulated population

\begin{tabular}{|c|c|c|c|}
\hline \multicolumn{2}{|l|}{ Median } & \multicolumn{2}{|c|}{ 5th percentile } \\
\hline $\mathrm{BMD}_{10}$ & $\mathrm{BMDL}_{10}$ & $\mathrm{BMD}_{10}$ & BMDL $_{10}$ \\
\hline 1.4 & 0.83 & 0.19 & 0.10 \\
\hline
\end{tabular}

the population, distinct dose-response relationships can be generated for distinct individuals. Therefore, no single $\mathrm{BMDL}_{10}$ value can be derived for the whole population. We performed reverse dosimetry for the median and the 5th percentile of our simulated target population, resulting in predicted dose-response data for these percentiles of this population (Fig. 6). These data and the results of dose-response modeling on these datasets using BMDS are shown in the supplementary Tables 13-16. The lowest
$\mathrm{BMDL}_{10}$ values for the median and the 5 th percentile of the simulated population amounted to 0.83 and $0.10 \mathrm{mg} \mathrm{kg}$ bw $^{-1}$, respectively (Table 3).

Comparing the predicted $\mathrm{BMDL}_{10}$ values for rat and human indicates that the predicted $\mathrm{BMDL}_{10}$ value for the median of the simulated human population is threefold higher than the predicted $\mathrm{BMDL}_{10}$ value for rat. The predicted $\mathrm{BMDL}_{10}$ for the 5 th percentile of the simulated human population is threefold lower than the predicted $\mathrm{BMDL}_{10}$ value for rat and eightfold lower than the predicted $\mathrm{BMDL}_{10}$ for the median of the simulated human population.

\section{Discussion}

The aim of the present study was to assess the feasibility of predicting dose-response data for in vivo developmental toxicity that can be used to obtain a POD for toxicological risk assessment, like a $\mathrm{BMDL}_{10}$, using a combined in vitro-in silico approach. Whereas earlier studies on this topic used industrial chemicals as model compounds with unspecific modes of actions and high in vitro effect concentrations (Louisse et al. 2010b; Strikwold et al. 2013), we used in the present study the pharmaceutical ATRA which has low in vitro effect concentrations and which has a specific, receptor-mediated mechanism underlying its toxicity [interfering with endogenous retinoid signaling pathways (Collins and Mao 1999)]. The results show that our predicted $\mathrm{BMDL}_{10}$ value differed about sixfold from the $\mathrm{BMDL}_{10}$ values that were obtained from in vivo data on ATRA-induced developmental toxicity, indicating that the combined in vitro-in silico approach is promising to be used to set PODs for the risk assessment of chemicals.

PBK model parameter values for kinetic processes are often obtained using in vivo kinetic data, but were in the present study mainly derived using in vitro techniques. Generally, the rat PBK model underpredicted ATRA plasma levels upon intravenous exposure and overpredicted ATRA plasma levels upon oral exposure, with all deviations within an order of magnitude (Fig. 3). This may be due to 
an overestimated prediction of distribution to peripheral tissues and to an overestimated intestinal absorption. Indeed, Morris tests revealed that these are among the parameters to which the model is the most sensitive. It must be noted, however, that the datasets from the literature show a large variation in in vivo ATRA plasma concentrations, indicating that there are possible differences in experimental conditions and/or experimental errors that can affect the reported plasma concentrations, which may explain part of the differences. Although we expected considerable uncertainty in measuring and scaling up metabolic turnover, and the model appeared to be sensitive to parameters related to metabolism, the metabolic clearance in rats seems to be well characterized by the model. The human ATRA plasma levels as reported by Adamson et al. (1993) were closely predicted by the human PBK model (Fig. 4). The variation of organ sizes, regional blood flows and enzyme expression in the model simulations explained a large part of the population variability in ATRA pharmacokinetics. Still some in vivo observations are outside the 5th and the 95th percentile of the simulated plasma concentrations of our simulated human population (Fig. 4). These could be attributed to sources of variability that were not included in the present simulations, such as gastrointestinal processes. It must be noted that we did not aim to develop a model that fits the in vivo kinetic data best. We rather aimed to demonstrate the development of a PBK model without the use of these in vivo kinetic datasets and use these data only for the evaluation of model performance. A more systematic analysis of the differences between predictions by PBK models that are based on in vitro data with in vivo kinetic data may give further insight in the uncertainties of the predictions made by these models. These uncertainties could then be integrated in the PBK model simulations to derive a conservative estimate of the POD for risk assessment. Alternatively, uncertainty factors can be derived that can be applied in a risk assessment strategy that would be based on a reverse dosimetry approach using models that are parameterized based on in vitro data.

Analysis of the $\mathrm{BMDL}_{10}$ values derived from predicted dose-response data and the $\mathrm{BMDL}_{10}$ values derived from in vivo developmental toxicity data on malformations indicates a better concordance when the toxic effect is related to the AUC than to the $C_{\max }$ of the compound. This is in line with the observations of an in vivo study with ATRAexposed rats, in which a better correlation was found when correlating various developmental toxicity endpoints to the AUC (correlation coefficients of $0.90-0.98$ ) than to the $C_{\max }$ (correlation coefficients of 0.22-0.43) (Tzimas et al. 1997). We obtained in vitro AUC values by multiplying the applied concentration in the ES-D3 cell differentiation assay with the assay time, as suggested by Daston et al. (2010). By doing so, it is assumed that the concentration of the test chemical in the exposure medium remains constant over time and that the sensitivity of the test system is constant as well. The influence of possible differences in chemical stability and sensitive periods on the extrapolation of in vitro toxicity data to the in vivo situation needs further research, but is beyond the scope of the present study. The fact, however, that deviations between $\mathrm{BMDL}_{10}$ values derived from predicted and observed in vivo dose-response data were limited, suggests that the approach taken provides a reasonable way of estimating the AUC related to ATRA-induced developmental toxicity.

In toxicological risk assessments, predicted $\mathrm{BMDL}_{10}$ values for rats could be used as the POD to set safe human exposure levels, applying uncertainty factors for interspecies and intraspecies differences in toxicokinetics and toxicodynamics. However, using predicted $\mathrm{BMDL}_{10}$ values for humans may reduce the need for uncertainty factors for inter- and intraspecies differences in kinetics. On the other hand, uncertainty factors related to the reverse dosimetry approach (for example, uncertainty in PBK model predictions or uncertainty in the sensitivity of the in vitro toxicity assays) should be introduced. Therefore, more studies are needed in order to quantify these uncertainties and set possible default values for these uncertainty factors.

Although the in vitro-in silico approach, as presented in this study, is promising to be used in the toxicological risk assessment of chemicals, there are some aspects for optimization. One is the prediction of effects upon repeated dose exposure. For ATRA, it has been shown that blood levels decrease upon repeated dosing (up to ninefold in rats) (Collins et al. 1995) due to increased expression levels of biotransformation enzymes (Collins et al. 1995; Tay et al. 2010). Therefore, we only considered ATRA-induced developmental toxicity for single dosing in the present study. In order to make predictions for ATRA-induced developmental toxicity after repeated dosing, the increase in expression levels of biotransformation enzymes should be incorporated in the PBK model, to account for these changes in clearance. This phenomenon needs further consideration in future reverse dosimetry work. Another aspect to consider in future reverse dosimetry approaches for developmental toxicity is the placental transfer of chemicals. In the present study, no specific compartment for the embryo was incorporated in the PBK model, because it has been reported that the embryo AUC of ATRA only slightly differs from the maternal plasma AUC of ATRA upon single dosing (Collins et al. 1995). However, the assumption of equal maternal and embryo levels cannot be made for all chemicals, indicating that in vitro placental transport models should be used in order to predict the placental transfer of these chemicals to the fetus. The in vitro BeWo b30 transwell system may be an adequate model to derive parameter values for placental transfer in PBK models (Li et al. 2013). 
Additionally, a clear approach of how to choose the dose metric $\left(C_{\max }\right.$ or AUC) to be chosen for the in vitro-in vivo extrapolation of unknown chemicals is needed. Finally, as we discussed before (Louisse et al. 2010a, 2012), the ESD3 cell differentiation assay may not produce the right in vitro effect concentrations for specific in vivo developmental toxicity endpoints, indicating that research is needed as to whether specific in vitro tests would be required for specific in vivo developmental toxicity endpoints. The in vitro ES-D3 cell differentiation assay used in the present study should be regarded as a simplified first tier model of the developing embryo and cannot be used to predict specific in vivo developmental toxicity end points with the greatest possible accuracy. One may consider, however, accommodating the consequences of the uncertainty of this approach within possible uncertainty factors generally applied in risk assessment.

Altogether, the present study shows the proof-of-concept that in vivo dose-response data for developmental toxicity can be predicted that can be used to set a POD for risk assessment, without the need of in vivo studies. It shows the feasibility of the reverse dosimetry approach, integrating in vitro and in silico techniques, to predict in vivo developmental toxicity dose levels. It is concluded that the combined in vitro-in silico approach has the potential to be used in toxicological risk assessment, thereby contributing to the 3 Rs of animal use.

Acknowledgments The authors would like to thank Harvey Clewell (The Hamner Institute for Health Sciences, USA) and Joost Westerhout (TNO, The Netherlands) for their contribution to discussions, Wouter Vaes and Jaap Jan Stevenhagen (TNO and TNO Triskelion, The Netherlands) for their help with the SPME studies, and Nicole Clemann (Roche, Switzerland) for providing the in vivo developmental toxicity data of Bürgin and Schmitt (2003). This work was supported by the Netherlands Organization for Health Research and Development (ZonMw; Project No. 114000088). B.J. Blaauboer received financial support from the Doerenkamp-Zbinden Foundation.

Conflict of interest The authors declare that they have no conflict of interest.

\section{References}

Adamson PC, Pitot HC, Balis FM, Rubin J, Murphy RF, Poplack DG (1993) Variability in the oral bioavailability of all-trans-retinoic acid. J Natl Cancer Inst 85:993-996

Ahmad M, Ahmadi M, Nicholls PJ, Smith HJ (2000) In-vitro metabolism of retinoic acid by different tissues from male rats. J Pharm Pharmacol 52:511-515

Beierschmitt WP, Weiner M (1986) Age-related changes in renal metabolism of acetaminophen in male fisher 344 rats. Age 9:7-13

Blaauboer BJ (2010) Biokinetic modeling and in vitro-in vivo extrapolations. J Toxicol Environ Health B Crit Rev 3:242-252

Bosgra S, van Eijkeren J, Bos P, Zeilmaker M, Slob W (2012) An improved model to predict physiologically based model parameters and their inter-individual variability from anthropometry. Crit Rev Toxicol 42:751-767

Brown RP, Delp MD, Lindstedt SL, Rhomberg LR, Beliles RP (1997) Physiological parameter values for physiologically based pharmacokinetic models. Toxicol Ind Health 13:407-484

Bürgin H, Schmitt G (2003) Comparison of the embryo-fetal toxicity of all-trans-retinoic acid in two strains of Wistar rat. In: Poster annual meeting European Teratology Society (data provided by Nicole Clemann)

Collins MD, Mao GE (1999) Teratology of retinoids. Annu Rev Pharmacol Toxicol 39:399-430

Collins MD, Tzimas G, Bürgin H, Hummler H, Nau H (1995) Single versus multiple dose administration of all-trans-retinoic acid during organogenesis: differential metabolism and transplacental kinetics in rat and rabbit. Toxicol Appl Pharmacol 130:9-18

Daston GP, Chapin RE, Scialli AR, Piersma AH, Carney EW, Rogers JM, Friedman JM (2010) A different approach to validating screening assays for developmental toxicity. Birth Defects Res B Dev Reprod Toxicol 89:526-530

Davies B, Morris T (1993) Physiological parameters in laboratory animals and humans. Pharm Res 10:1093-1095

DeJongh J, Nordin-Andersson M, Ploeger BA, Forsby A (1999) Estimation of systemic toxicity of acrylamide by integration of in vitro toxicity data with kinetic simulations. Toxicol Appl Pharmacol 158:261-268

El Mansouri S, Tod M, Leclerq M, Petitjean O, Perret G, Porthault M (1995) Time- and dose-dependent kinetics of all-trans-retinoic acid in rats after oral or intravenous administration(s). Drug Metab Dispos 23:227-231

Forsby A, Blaauboer BJ (2007) Integration of in vitro neurotoxicity data with biokinetic modelling for the estimation of in vivo neurotoxicity. Hum Exp Toxicol 26:333-338

Gülden M, Dierickx P, Seibert H (2006) Validation of a prediction model for estimating serum concentrations of chemicals which are equivalent to toxic concentrations in vitro. Toxicol In Vitro 20:1114-1124

Hosseinpour M, Behdad A (2008) Evaluation of small bowel measurement in alive patients. Surg Radio Anat 30:653-655

Kararli TT (1995) Comparison of the gastrointestinal anatomy, physiology, and biochemistry of humans and commonly used laboratory animals. Biopharm Drug Dispos 16:351-380

Kharasch ED, Walker A, Isoherranen N, Hoffer C, Sheffels P, Thummel K, Whittington D, Ensign D (2007) Influence of CYP3A5 genotype on the pharmacokinetics and pharmacodynamics of the cytochrome $\mathrm{P} 4503 \mathrm{~A}$ probes alfentanil and midazolam. Clin Pharmacol Ther 82:410-426

Lee HB, Blaufox MD (1985) Blood volume in the rat. J Nucl Med 26:72-76

Li H, van Ravenzwaay B, Rietjens IMCM, Louisse J (2013) Assessment of an in vitro transport model using BeWo b30 cells to predict placental transfer of compounds. Arch Toxicol 87:1661-1669

Lin YS, Dowling ALS, Quigley SD, Farin FM, Zhang J, Lamba J, Schuetz AG, Thummel KE (2002) Co-regulation of CYP3A4 and CYP3A5 and contribution to hepatic and intestinal midazolam metabolism. Mol Pharmacol 62:162-172

Little JM, Lehman PA, Nowell S, Samokyszyn V, Radominska A (1997) Glucuronidation of all-trans-retinoic acid and 5,6-epoxyall-trans-retinoic acid. Activation of rat liver microsomal UDPglucuronosyltransferase activity by alamethicin. Drug Metab Dispos 25:5-11

Louisse J, de Jong E, van de Sandt JJM, Blaauboer BJ, Woutersen RA, Piersma AH, Rietjens IMCM, Verwei M (2010a) The use of in vitro toxicity data and physiologically based kinetic modeling to predict dose-response curves for in vivo developmental toxicity of glycol ethers in rat and man. Toxicol Sci 118:470-484 
Louisse J, Bai Y, Verwei M, van de Sandt JJM, Blaauboer BJ, Rietjens IMCM (2010b) Decrease of intracellular pH as possible mechanism of developmental toxicity of glycol ether alkoxyacetic acid metabolites. Tox Appl Pharm 245:236-243

Louisse J, Gönen S, Rietjens IMCM, Verwei M (2011) Relative developmental toxicity potencies of retinoids in the embryonic stem cell test compared with their relative potencies in in vivo and two other in vitro assays for developmental toxicity. Toxicol Lett 203:1-8

Louisse J, Verwei M, Woutersen RA, Blaauboer BJ, Rietjens IMCM (2012) Toward in vitro biomarkers for developmental toxicity and their extrapolation to the in vivo situation. Expert Opin Drug Metab Toxicol 8:11-27

Lutz JD, Dixit V, Yeung CK, Dickmann LJ, Zelter A, Thatcher JE, Nelson WL, Isoherranen N (2009) Expression and functional characterization of cytochrome P450 26A1, a retinoic acid hydroxylase. Biochem Pharmacol 77:258-268

McConnell EL, Basit AW, Murdan S (2008) Measurements of rat and mouse gastrointestinal $\mathrm{pH}$, fluid and lymphoid tissue, and implications for in vivo experiments. J Pharm Pharmacol 60:63-70

McNally K, Cotton R, Loizou GD (2011) A workflow for global sensitivity analysis of PBPK models. Front Pharmacol 23:31

Medinsky MA, Leavens TL, Csanady GA, Gargas ML, Bond JA (1994) In vivo metabolism of butadiene by mice and rats: a comparison of physiological model predictions and experimental data. Carcinogenesis 15:1329-1340

Naraharisetti SB, Lin YS, Rieder MJ, Marciante KD, Psaty BM, Thummel KE, Totah RA (2010) Human liver expression of CYP2C8: gender, age, and genotype effects. Drug Metab Dispos 38:889-893

Paini A, Punt A, Viton F, Scholz G, Delatour T, Marin-Kuan M, Schilter B, van Bladeren PJ, Rietjens IMCM (2010) A physiologically based biodynamic (PBBD) model for estragole DNA binding in rat liver based on in vitro kinetic data and estragole DNA adduct formation in primary hepatocytes. Toxicol Appl Pharmacol 245:57-66

Ravindranath V, Anandatheerthavarada HK (1990) Preparation of brain microsomes with cytochrome $\mathrm{P} 450$ activity using calcium aggregation method. Anal Biochem 187:310-313

Reilly JA Jr, Forst CF, Quigley EM, Rikkers LF (1990) Gastric emptying of liquids and solids in the portal hypertensive rat. Dig Dis Sci 35:781-786

Rietjens IMCM, Louisse J, Punt A (2011) Tutorial on physiologically based kinetic modeling in molecular nutrition and food research. Mol Nutr Food Res 55:941-956

Rotroff DM, Wetmore BA, Dix DJ, Ferguson SS, Clewell HJ, Houck KA, Lecluyse EL, Andersen ME, Judson RS, Smith CM, Sochaski MA, Kavlock RJ, Boellmann F, Martin MT, Reif DM, Wambaugh JF, Thomas RS (2010) Incorporating human dosimetry and exposure into high-throughput in vitro toxicity screening. Toxicol Sci 117:348-358

Samokyszyn VM, Gall WE, Zawada G, Freyaldenhoven MA, Chen G, Mackenzie PI, Tephly TR, Radominska-Pandya A (2000) 4-Hydroxyretinoic acid, a novel substrate for human liver microsomal UDP-glucuronosyltransferase(s) and recombinant UGT2B7. J Biol Chem 275:6908-6914

Shelley RS, Jun HW, Price JC, Cadwallader DE (1982) Blood level studies of all-trans- and 13-cis-retinoic acids in rats using different formulations. J Pharm Sci 71:904-907

Sim SC, Edwards RJ, Boobis AR, Ingelman-Sundberg M (2005) CYP3A7 protein expression is high in a fraction of adult human livers and partially associated with the CYP3A7*1C allele. Pharmacogenet Genomics 15:625-631
Smith JE, Milch PO, Muto Y, Goodman DS (1973) The plasma transport and metabolism of retinoic acid in the rat. Biochem $\mathrm{J}$ 132:821-827

Strikwold M, Spenkelink B, Woutersen RA, Rietjens IMCM, Punt A (2013) Combining in vitro embryotoxicity data with physiologically based kinetic (PBK) modelling to define in vivo doseresponse curves for developmental toxicity of phenol in rat and human. Arch Toxicol 87:1709-1723

Sun WM, Houghton LA, Read NW, Grundy DG, Johnson AG (1988) Effect of meal temperature on gastric emptying of liquids in man. Gut 29:302-305

Sun D, Lennernas H, Welage LS, Barnett JL, Landowski CP, Foster D, Fleisher D, Lee KD, Amidon GL (2002) Comparison of human duodenum and Caco-2 gene expression profiles for 12,000 gene sequences tags and correlation with permeability of 26 Drugs. Pharm Res 19:1400-1416

Swanson BN, Frolik CA, Zaharevitz DW, Roller PP, Sporn MB (1981) Dose-dependent kinetics of all-trans-retinoic acid in rats. Plasma levels and excretion into bile, urine, and faeces. Biochem Pharmacol 30:107-113

Tay S, Dickmann L, Dixit V, Isoherranen N (2010) A comparison of the roles of peroxisome proliferator-activated receptor and retinoic acid receptor on CYP26 regulation. Mol Pharmacol $77: 218-227$

Thatcher JE, Zelter A, Isoherranen N (2010) The relative importance of CYP26A1 in hepatic clearance of all-trans retinoic acid. Biochem Pharmacol 80:903-912

Tzimas G, Thiel R, Chahoud I, Nau H (1997) The area under the concentration-time curve of all-trans-retinoic acid is the most suitable pharmacokinetic correlate to the embryotoxicity of this retinoid in the rat. Toxicol Appl Pharmacol 143:436-444

Vaes W (2010) Assay system for determining binding of hydrophobic drugs. Patent no. WO/2010/117276

Van der Jagt K, Munn SJ, Tørsløv J, de Bruijn J (2004) Alternative approaches can reduce the use of test animals under REACH. Report EUR 21405

Verwei M, van Burgsteden JA, Krul CAM, van de Sandt JJM, Freidig AP (2006a) Prediction of in vivo embryotoxic effect levels with a combination of in vitro studies and PBPK modelling. Toxicol Lett 165:79-87

Verwei M, Freidig AP, Havenaar R, Groten JP (2006b) Predicted serum folate concentrations based on in vitro studies and kinetic modeling are consistent with measured folate concentrations in humans. J Nutr 136:3074-3078

Wetmore BA, Wambaugh JF, Ferguson SS, Sochaski MA, Rotroff DM, Freeman K, Clewell HJ 3rd, Dix DJ, Andersen ME, Houck KA, Allen B, Judson RS, Singh R, Kavlock RJ, Richard AM, Thomas RS (2012) Integration of dosimetry, exposure, and highthroughput screening data in chemical toxicity assessment. Toxicol Sci 125:157-174

Wise LD, Xue D, Winkelmann CT (2010) Micro-computed tomographic evaluation of fetal skeletal changes induced by all-transretinoic acid in rats and rabbits. Birth Defects Res B Dev Reprod Toxicol 89:408-417

Wolbold R, Klein K, Burk O, Nüssler AK, Neuhaus P, Eichelbaum M, Schwab M, Zanger UM (2003) Sex is a major determinant of CYP3A4 expression in human liver. Hepatology 38:978-988

Zaya MJ, Hines RN, Stevens JC (2006) Epirubin glucuronidation and UGT2B7 developmental expression. Drug Metabol Dispos 34:2097-2101

Zimmerman CL, Han S, Wiedmann TS (2001) The absorption of retinoic acids from the gastrointestinal tract is dependent upon chemical structure. Cancer Chemother Pharmacol 47:27-33 